\title{
microRNA-155 Regulates Alpha-Synuclein-Induced Inflammatory Responses in Models of Parkinson Disease
}

\author{
Aaron D. Thome, Asshley S. Harms, ㄴara A. Volpicelli-Daley, and David G. Standaert \\ Center for Neurodegeneration and Experimental Therapeutics, Department of Neurology, The University of Alabama at Birmingham, Birmingham, \\ Alabama 35294
}

Increasing evidence points to inflammation as a chief mediator of Parkinson's disease (PD), a progressive neurodegenerative disorder characterized by loss of dopamine neurons in the substantia nigra pars compacta $(\mathrm{SNpc})$ and widespread aggregates of the protein $\alpha$-synuclein ( $\alpha$-syn). Recently, microRNAs, small, noncoding RNAs involved in regulating gene expression at the posttranscriptional level, have been recognized as important regulators of the inflammatory environment. Using an array approach, we found significant upregulation of microRNA-155 (miR-155) in an in vivo model of PD produced by adeno-associated-virus-mediated expression of $\alpha$-syn. Using a mouse with a complete deletion of miR-155, we found that loss of miR-155 reduced proinflammatory responses to $\alpha$-syn and blocked $\alpha$-syn-induced neurodegeneration. In primary microglia from miR-155 $5^{-1-}$ mice, we observed a markedly reduced inflammatory response to $\alpha$-syn fibrils, with attenuation of major histocompatibility complex class II (MHCII) and proinflammatory inducible nitric oxide synthase expression. Treatment of these microglia with a synthetic mimic of miR-155 restored the inflammatory response to $\alpha$-syn fibrils. Our results suggest that miR-155 has a central role in the inflammatory response to $\alpha$-syn in the brain and in $\alpha$-syn-related neurodegeneration. These effects are at least in part due to a direct role of miR-155 on the microglial response to $\alpha$-syn. These data implicate miR-155 as a potential therapeutic target for regulating the inflammatory response in PD.

Key words: $\alpha$-synuclein; microglia; microRNA-155; neurodegeneration; neuroinflammation; Parkinson disease

Significance Statement

The main feature associated with Parkinson's disease (PD) is the accumulation of $\alpha$-synuclein in the brain accompanied by signs of inflammation and immune activation. Our studies suggest that microRNA-155 is a key inflammation-initiating molecule that could be a viable target for PD therapeutics.

\section{Introduction}

Parkinson's disease (PD) is the most common neurodegenerative movement disorder and is characterized by the progressive loss of dopamine-producing neurons in the substantia nigra pars compacta $(\mathrm{SNpc})$ along with widespread intracellular aggregates of the protein $\alpha$-synuclein ( $\alpha$-syn). Increasing evidence points to neuroinflammation as a chief mediator in the pathogenesis and progression of PD (McGeer et al., 1988; Hirsch and Hunot, 2009; Appel, 2012). Analysis of postmortem brain and CSF from PD

\footnotetext{
Received 0ct. 28, 2015; revised Dec. 30, 2015; accepted Jan. 12, 2016.

Author contributions: A.D.T., A.S.H., and D.G.S. designed research; A.D.T. and A.S.H. performed research; L.A.V.-D. contributed unpublished reagents/analytic tools; A.D.T., A.S.H., and D.G.S. analyzed data; A.D.T., A.S.H., and D.G.S. wrote the paper.

This work was supported by the American Parkinson Disease Association, the National Institute of Neurological Disorders and Stroke-National Institutes of Health (Grants F31 NS084722 and NINDS P20 NS092530).

The authors declare no competing financial interests.

Correspondence should be addressed to Dr. David G. Standaert, Professor and Chair of Neurology, John N. Whitaker Endowed Chair, University of Alabama at Birmingham (UAB), 1719 6th Ave. South, CIRC 516, Birmingham, AL 35294-0021. E-mail: dstandaert@uab.edu.

DOI:10.1523/JNEUROSCI.3900-15.2016

Copyright $\odot 2016$ the authors $\quad 0270-6474 / 16 / 362383-08 \$ 15.00 / 0$
}

patients showed increased proinflammatory cytokines such as TNF, IL-1 $\beta$, IL-6, and IFN- $\gamma$ (Mogi et al., 1994a; Mogi et al., 1994b). Along with these findings, extensive microgliosis (McGeer et al., 1988; Gerhard et al., 2006) and T-cell infiltration (Brochard et al., 2009) are present, indicating a proinflammatory microenvironment. Genome-wide association studies implicate polymorphisms in the MHC class II cell surface receptor HLA-DR in late-onset, idiopathic PD (Hamza et al., 2010). Studies in acute and chronic animal model systems of PD replicate many of these same findings. Viral [adeno-associated virus 2 (AAV2)-SYN], neurotoxin, and transgenic models of PD in mouse, rat, and nonhuman primates recapitulate the reactive microgliosis, elevated cytokine expression, lymphocyte invasion, and gradual loss of dopaminergic (tyrosine hydroxylase-positive, $\mathrm{TH}^{+}$) cells in the SNpc (Ramsey and Tansey, 2014; Allen Reish and Standaert, 2015). We have reported previously that the inflammatory and neurodegenerative effects of $\alpha$-syn can be attenuated by blockade of several components of the inflammatory cascade, including components of the MHCII, fractalkine receptor (CX3CR1) signaling, and the microglial signaling molecule 
Fcgamma (Cao et al., 2010; Cao et al., 2012; Harms et al., 2013; Thome et al., 2015). As a result of these and other observations, immunomodulatory strategies have emerged as a potentially valuable class of therapeutic interventions in PD.

MicroRNAs are important regulators of gene expression and modulators of inflammatory responses. They act at the posttranscriptional level by targeting the $3^{\prime}$ untranslated region of messenger RNAs (mRNAs), resulting in translational repression or degradation of the target. Several different microRNAs have been implicated as important regulators and fine tuners of immune system activation and neuroinflammation. Sustained aberrant microRNA expression levels have been described in inflammatory and immune-related neurodegenerative disorders including multiple sclerosis (MS) (Junker et al., 2009; Moore et al., 2013), amyotrophic lateral sclerosis (ALS) (Butovsky et al., 2012; Koval et al., 2013), and Alzheimer's disease (AD) (Femminella et al., 2015). To date, there have been few studies of the role microRNAs in PD patients or models of PD.

One of the key microRNA modulators of neuroinflammation is microRNA-155 (miR-155), which has been shown to have strong proinflammatory effects. miR- 155 is induced by stimuli such as LPS, IFN- $\gamma$, and TNF and contributes to proinflammatory signaling cascades and effector functions by inhibiting FADD, SOCS1, IKK, IL13R $\alpha 1$, and SMAD2, which collectively result in upregulation of the proinflammatory molecules IL-1, IL-6, TNF- $\alpha$, and inducible nitric oxide synthase (iNOS) (Louafi et al., 2010; Liu and Abraham, 2013; Ponomarev et al., 2013; Yang et al., 2015). MiR-155 also acts to suppress anti-inflammatory targets such as CEBP $\beta$ and SHIP1, which leads to decreases in the IL-10, Arg1, IL13R, and TGF $\beta$ R pathways (O'Connell et al., 2009).

In this study, we used a PCR-based screening method to examine the expression of microRNAs related to immune function in the AAV2-SYN mouse model of PD and discovered that there is upregulation of miR-155 in this model. This led to a more detailed examination of the role of miR-155 in $\alpha$-syn-induced neuroinflammation and neurodegeneration using mice with genetic deletion of miR-155. Our data show that miR-155 is indeed centrally related to the inflammatory processes triggered by $\alpha$-syn and that blockade of miR-155 can protect against $\alpha$-synmediated neurodegeneration.

\section{Materials and Methods}

Animals. C57BL/6 (catalog \#000664; Jackson Laboratories) and miR$155^{-1-}$ mice (B6.Cg-Mir155tm1.1Rsky/J, catalog \#007745; Jackson Laboratories) (Thai et al., 2007) maintained on a congenic background were used for these studies.

$A A V 2$ virus construction and purification. Construction and purification of the rAAV vectors rAAV-CBA-IRES-EGFP-WPRE (CIGW) and rAAV-CBA-SYN UCLEIN-IRES-EGFP-WPRE (CSIGW) have been described previously (St Martin et al., 2007; Theodore et al., 2008; Cao et al., 2012). AAV2-SYN injection into the mouse SNpc results in a marked increase in both $\alpha$-syn mRNA (St Martin et al., 2007) and protein expression (Harms et al., 2013). Both monomeric species and high-molecularweight forms are seen in nigral tissue in vivo (Harms et al., 2013).

Stereotaxic surgery. Male C57BL/6 (WT) and miR-155 $5^{-1-}$ mice $(8-12$ weeks of age) were anesthetized with isoflurane and unilaterally injected with $2 \mu \mathrm{l}$ of AAV2-SYN or AAV2-GFP $\left(4.0 \times 10^{12}\right.$ viral genome $/ \mathrm{ml}$ diluted in sterile PBS) into the right SNpc. Coordinates were anteriorposterior $-3.2 \mathrm{~mm}$ from bregma, mediolateral $+1.2 \mathrm{~mm}$ from midline, and dorsoventral $-4.6 \mathrm{~mm}$ from dura. All research conducted on animals was approved by the Institutional Animal Care and Use Committee at the University of Alabama at Birmingham.

Quantitative PCR and mouse inflammatory miRNA PCR array. At 2 and 4 weeks after transduction, animals were deeply anesthetized and SNpc were dissected ( $n=6$ per group), flash frozen using liquid nitro- gen, and stored at $-80 \mathrm{C}$ for processing. Total RNA was isolated using the Qiagen miRNeasy mini kit (catalog \#217004) according to the manufacturer's protocol. RNA concentrations were determined using the Nanodrop ND1000 Spectrophotometer. RNA was then transcribed into cDNA using Qiagen miScript RT kit (catalog \#218161). miR-155 specific probes (Applied Biosystems, catalog \#4427975) were used and samples were run on the Applied Biosystems 7900HT Fast RealTime PCR System with snoRNA-135 as the control. For the PCR array, the extraction of the SNpc, RNA isolation, and cDNA was generated as described above ( $n=6$ per group). Reaction mixes were pooled according to their specific group and added into the Inflammatory Response and Autoimmunity miScript PCR Array (Qiagen, MIMM-105Z). The reaction was run according to the manufacturer's protocol. The plate allowed us to assess changes in gene expression of 84 different microRNAs relative to inflammation and immune response pathways ( $n=4$ per microRNA per pooled sample). Abundant controls are included in the plate including six snoRNA/ snRNAs, three mature miRNAs that are ubiquitously expressed, and an exogenously spiked Syn-cel-miR-39 for alternative data normalization. Data were analyzed using software provided by Qiagen specific to these assays (http://pcrdataanalysis.sabiosciences.com/mirna).

Immunohistochemistry. At 4 weeks and 6 months after transduction, animals were deeply anesthetized, killed, and brains were removed and processed. Briefly, animals were transcardially perfused with heparinized 0.01 м PBS, pH 7.4, followed by 4\% paraformaldehyde and then cryoprotected in $30 \%$ sucrose solution in PBS. Brains were frozen on dry ice and cryosectioned coronally on a sliding microtome (cut thickness: 40 $\mu \mathrm{m}$ ); sections were collected serially throughout the striatum and SNpc, placed into tissue collection solution ( $50 \%$ glycerol in $0.01 \mathrm{M} \mathrm{PBS}$ ), and stored at $-20^{\circ} \mathrm{C}$ for immunohistochemical analysis.

Fluorescent analyses of free-floating sections were labeled as described previously (Harms et al., 2013). Sections were labeled with anti-MHCII (1:100, M5/114.15.2; eBiosciences), anti-GFP (1:1000; Rockland), antiCD68 (1:500; AbD Serotec), or anti-TH (1:2000; Millipore) overnight at $4^{\circ} \mathrm{C}$. Respective Alexa Fluor-conjugated secondary antibodies diluted at 1:1000 (Invitrogen) or Cy3-conjugated antibodies (1:500; Jackson ImmunoResearch) were used at room temperature for $2.5 \mathrm{~h}$. Sections were mounted onto glass slides and coverslipped using Vectashield Hard Set mounting medium.

For diaminobenzadine (DAB) staining, sections were washed and stained with Tris-buffered saline (TBS), $\mathrm{pH} 7.4$, and labeled as described previously (Harms and Tansey, 2013). Briefly, anti-MHCII (, 1:100, M5/ 114.15.2; eBiosciences) or anti-TH (1:2000; Millipore) were diluted in TBS-Triton (TBST) $+1 \%$ normal serum and incubated overnight at $4^{\circ} \mathrm{C}$. Biotinylated secondary antibody (1:500; Vector Laboraties) was added in TBST $+1 \%$ serum and incubated for $2 \mathrm{~h}$ at room temperature. R.T.U. Vectastain ABC reagent (Vector Laboratories) and the DAB kit from (SK-4100; Vector Laboratories) were used according to the manufacturer's instructions. Sections were mounted onto glass slides and coverslipped using Vectashield Hard Set mounting medium.

For TH neuron quantification using unbiased stereology, sections were stained with anti-TH (Millipore, 1:2000), coded, and analyzed with an Olympus BX51 with MicroBrightfield software. Five sections covering the rostrocaudal extent of the SNpc of ipsilateral and contralateral to the injection site were quantified using the optical fractionator method and StereoInvestigator software. Neurons that stained positive for TH were counted and weighted section thickness was used to correct for variations in tissue thickness.

Imaging and quantification. Images were captured using a Leica TCSSP5 laser scanning confocal microscope. For quantification of MHCII $\mathrm{Ni}$-DAB staining, slides were coded and scored using a numerical scale of 0 (no staining) to 4 (most intense staining) by a single observer blind to the treatment paradigm. Only MHCII staining surrounding the SNpc composed of $\mathrm{TH}^{+}$neurons (DAB-brown) were scored; nonspecific staining surrounding the needle tract was ignored. Scores were obtained from five to six mice per group. Statistics were analyzed using KruskalWallis and Dunn's multiple-comparisons tests.

Primary microglia cultures. Primary murine microglia were isolated from postnatal day $0-2$ pups according to previously published proto- 
A
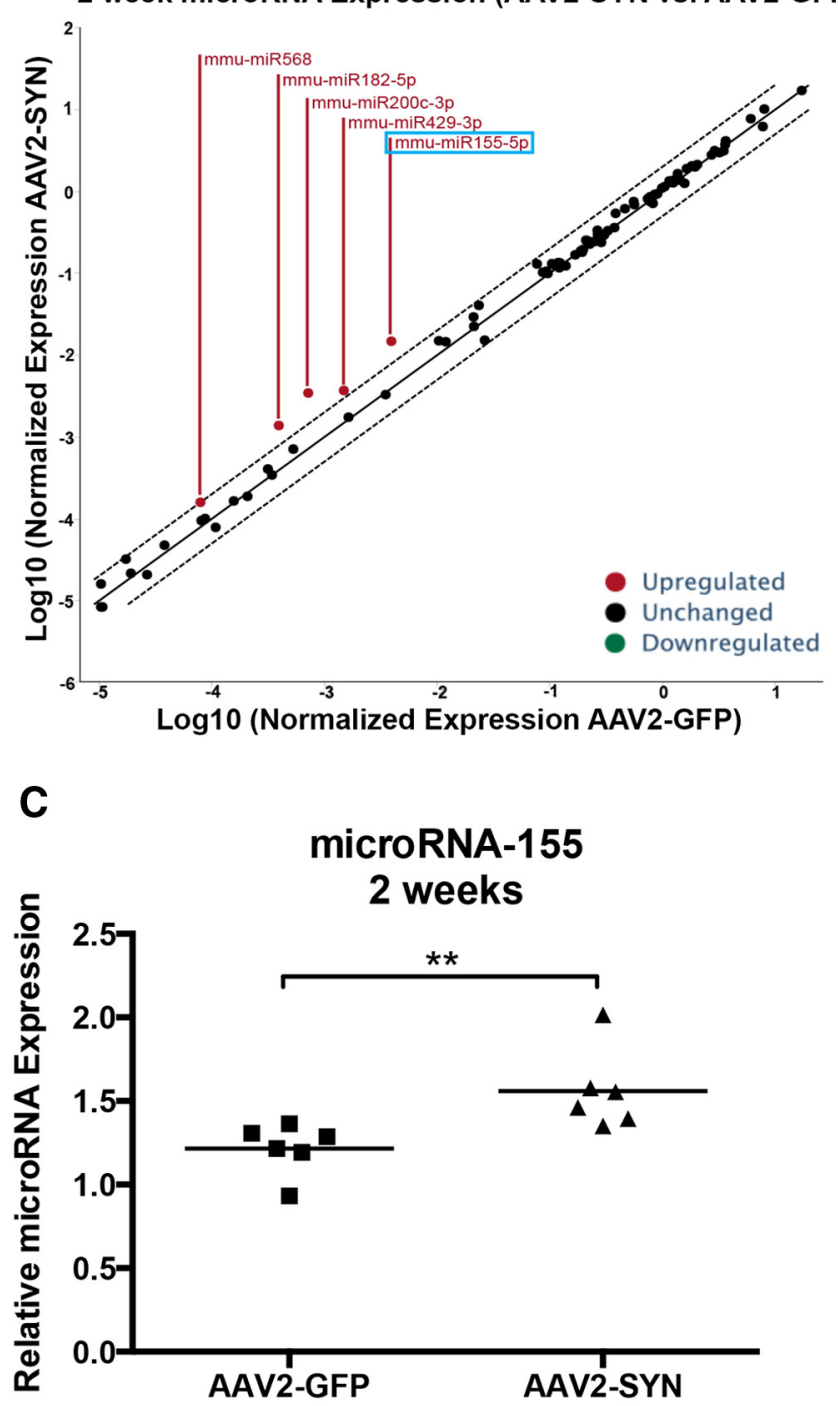

B

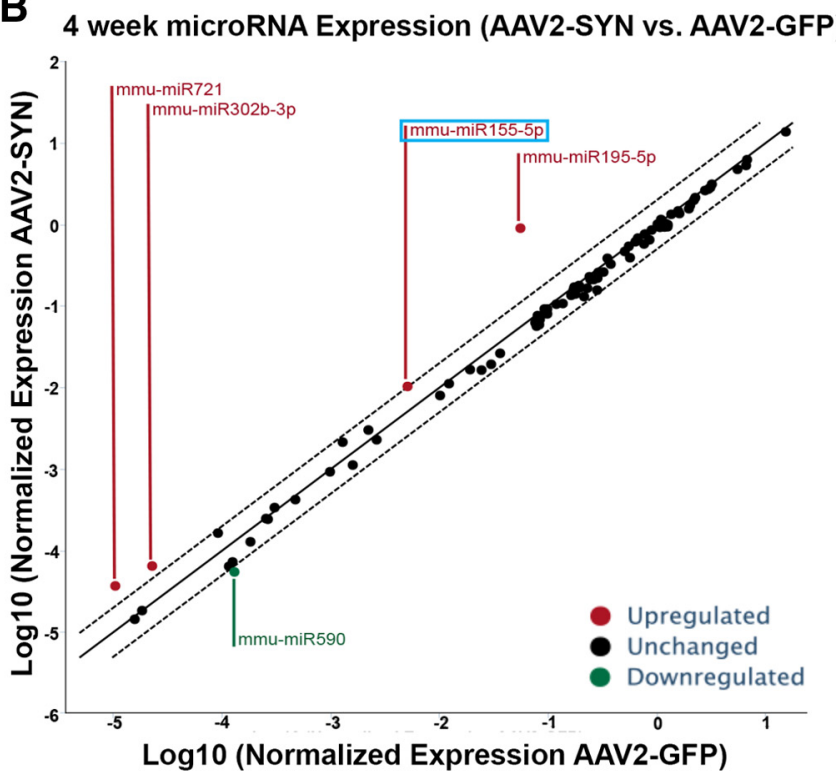

D

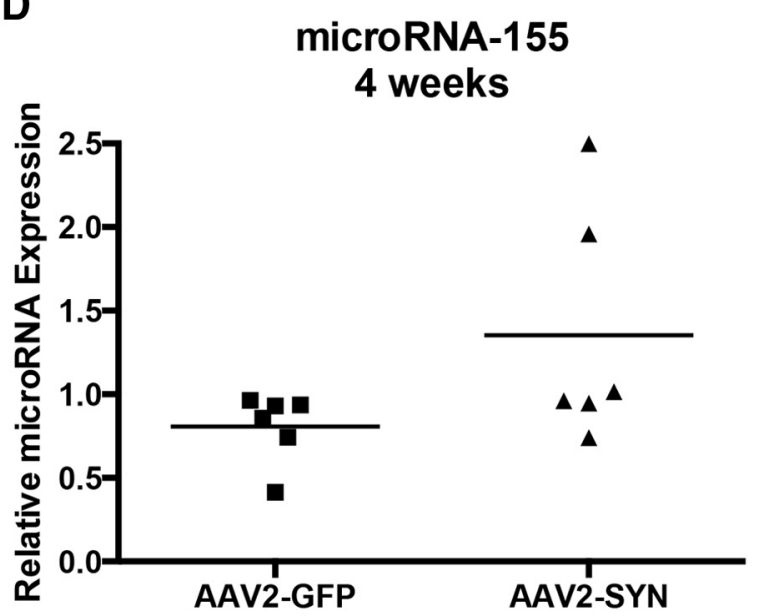

Figure 1. AAV2-SYN overexpression induces microRNA-155 in the SNpc. $A, B$, Multiple microRNAs are increased at 2 weeks and 4 weeks after transduction of AAV2-SYN compared with AAV-GFP-injected animals. miR-155 was found to be increased at both time points. microRNAs were measured and quantified using the Qiagen Inflammatory Response and Autoimmunity miScript miRNA PCR array and miScript PCR Array Data Analysis Tool. Samples were pooled from $n=6$ animals per group with four replicates of each group per plate. $C, D$, Increased miR-155 expression confirmed at 2 weeks after transduction of AAV2-SYN using probes designed for the mature miR-155 sequences. Animals were studied individually using $n=6$ animals per group. At 2 weeks, miR-155 was significantly increased ( $p=0.0144$, Student's $t$ test). At 4 weeks, there was a trend for increased miR-155 that did not reach significance $(p=0.0688$, Student's $t$ test).

cols (Harms et al., 2013) with a few modifications. Briefly, brains were isolated and meninges were removed and dissociated for $10 \mathrm{~min}$ at $37^{\circ} \mathrm{C}$ with frequent agitation. Mixed glial populations were filtered through a $0.2 \mu \mathrm{m}$ filter and plated in T75 flasks in DMEM/F12 supplemented with $20 \%$ heat inactivated fetal bovine serum (Sigma-Aldrich), $1 \%$ penicillin/ streptomycin, $1 \%$ L-glutamine (Sigma-Aldrich), and $10 \mathrm{ng} / \mathrm{ml}$ granulocyte monocyte colony stimulating factor (PeproTech) for 10-14 d. Microglia were isolated from the astrocyte bed by mechanical shaking at $195 \mathrm{rpm}$ for $1 \mathrm{~h}$ at $37^{\circ} \mathrm{C}$.

$\alpha$-syn fibril preparation. Preparations of human $\alpha$-syn preformed fibrils were produced and purified as described previously (VolpicelliDaley et al., 2014) and then stored at $-80^{\circ} \mathrm{C}$. Each preparation of was analyzed using thioflavin T fluorimetry, sedimentation at $100,000 \times g$, and electron microscopy as described previously (Luk et al., 2009; Luk et al., 2012a; Volpicelli-Daley et al., 2014). Average thioflavin T binding was $8706 \pm 540 \mathrm{AU}$ for fibrils and $1275 \pm 52 \mathrm{AU}$ for monomer. To make the working solution of preformed fibrils, $20 \mu \mathrm{l}$ of $5 \mathrm{mg} / \mathrm{ml}$ stock solution was diluted into $980 \mu \mathrm{l}$ of sterile PBS. The fibrils were sonicated using a Fisher Scientific Sonic Dismembrator Model 500 with a program consisting of sonication at $10 \%$ power for $30 \mathrm{~s}$ at intervals of $0.5 \mathrm{~s}$ on/off. The control used for the experiment was human $\alpha$-syn monomer that is stored at $-80^{\circ} \mathrm{C}$ to prevent aggregation and then maintained on ice until addition into media. Monomer was centrifuged at $4^{\circ} \mathrm{C}$ at $30,000 \times g$ for $10 \mathrm{~min}$ and supernatant was added to the cells.

$\alpha$-syn fibril and miR-155 mimic experiments. Dissected microglia were plated in chamber slides (Lab-Tek II Chamber Slides) at 100,000 cells per well with serum-free medium. Before assays, microglia were allowed to settle onto chamber slide for $2 \mathrm{~h}$, followed by replenishing chambers with fresh medium. Sonicated, preformed $\alpha$-syn fibrils $(200 \mathrm{ng} / \mathrm{ml})$ or $\alpha$-syn monomer was added into media in the chambers for $2 \mathrm{~h}$. Mature sequence miR-155 oligonucleotide mimic was obtained from Qiagen (Syn-mmumiR-155-5p, MSY0000165). The miR-155 mimic was added to the medium at $1 \mathrm{pm}$ with the addition of HiPerFect transfection reagent (Qiagen, catalog \#301705) per the manufacturer's protocol. After incubation overnight with miR-155 mimic ( $18 \mathrm{~h}$ ), preformed $\alpha$-syn fibrils or $\alpha$-syn monomer was added into media in the chambers for $2 \mathrm{~h}$. Cells were then fixed with $2 \%$ paraformaldehyde in 0.01 PBS and washed with PBS 3 times.

Immunocytochemistry. Microglia cells treated with $\alpha$-syn fibrils or $\alpha$-syn monomer were stained as described previously (Harms et al., 2013) with either anti-MHCII (1:100, M5/114.15.2; eBiosciences) or 
anti-iNOS (ab3523, 1:100; Abcam). Imaging was performed using a Leica TCS-SP5 laser scanning confocal microscope. Images were captured for a total of four pictures per chamber well per slide with $\sim 30-40$ microglia per image. Quantification was taken with the independent variable being the individual chamber ( $n=4$ per slide/treatment) using ImageJ software to quantify the mean fluorescence of the individual cell staining.

\section{Results}

Overexpression of $\alpha$-syn via AAV2-SYN induces expression of miR-155 in vivo We began our investigation by studying the expression of 84 inflammation- and autoimmune-associated microRNAs using a miScript PCR Array and the AAV2-SYN mouse model of PD. Two and 4 weeks after transduction with either AAV2-SYN or an AAV2-GFP control vector, we isolated total RNA from the ipsilateral SNpc. Several of the microRNAs demonstrated enhanced expression at either the early or later time point; however, miR-155 demonstrated enhanced expression at both 2 and 4 weeks. (Fig. $1 A, B$ ). To validate this result, we performed quantitative PCR with TaqMan probes targeted at mature miR-155. We found that, at 2 weeks after AAV-SYN administration, miR-155 was upregulated by $30 \%$ ( $p=0.0144, n=6$ per group). At 4 weeks, this method demonstrated a trend toward increased expression of miR-155, but the variance among animals was greater and the increase did not reach statistical significance $(p=0.0688, n=6$ per group; Fig. $1 C, D)$.

\section{miR-155 is critical for MHCII}

expression and microgliosis in response to overexpression of $\alpha$-syn in vivo

The observation that miR-155 was elevated early after $\alpha$-syn expression led us to investigate whether miR-155 participates in the inflammation and neurodegeneration seen in this model. For these studies, we used a mouse with genetic deletion of miR-155, as described previously (Thai et al., 2007). After injection of either AAV2-GFP or AAV2-SYN, we used immunohistochemistry for MHCII and CD68, markers of reactive microgliosis. Four weeks after transduction, we observed a significant increase of MHCII expression (Fig. 2A,C) in WT mice infected with AAV2-SYN, but not in mice transfected with AAV2-GFP ( $n=6$ per group). In contrast to this, we found no increase in MHCII expression in miR-155 ${ }^{-1-}$ mice after either AAV2-GFP or AAV2-SYN transduction. Similarly, staining for CD68 was also increased in WT animals transduced with AAV2-SYN, but no enhancement of CD68 was seen in the

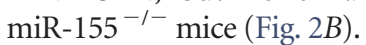

miR-155 knock-out prevents $\alpha$-syn-associated neurodegeneration

To test the effect of miR-155 on neurodegeneration, we examined the effects of AAV2-SYN on dopamine neuron number in the
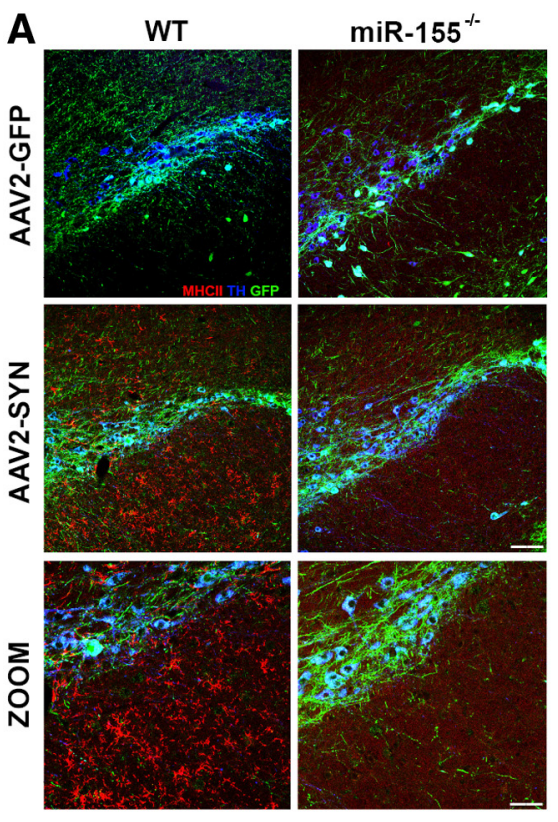

B
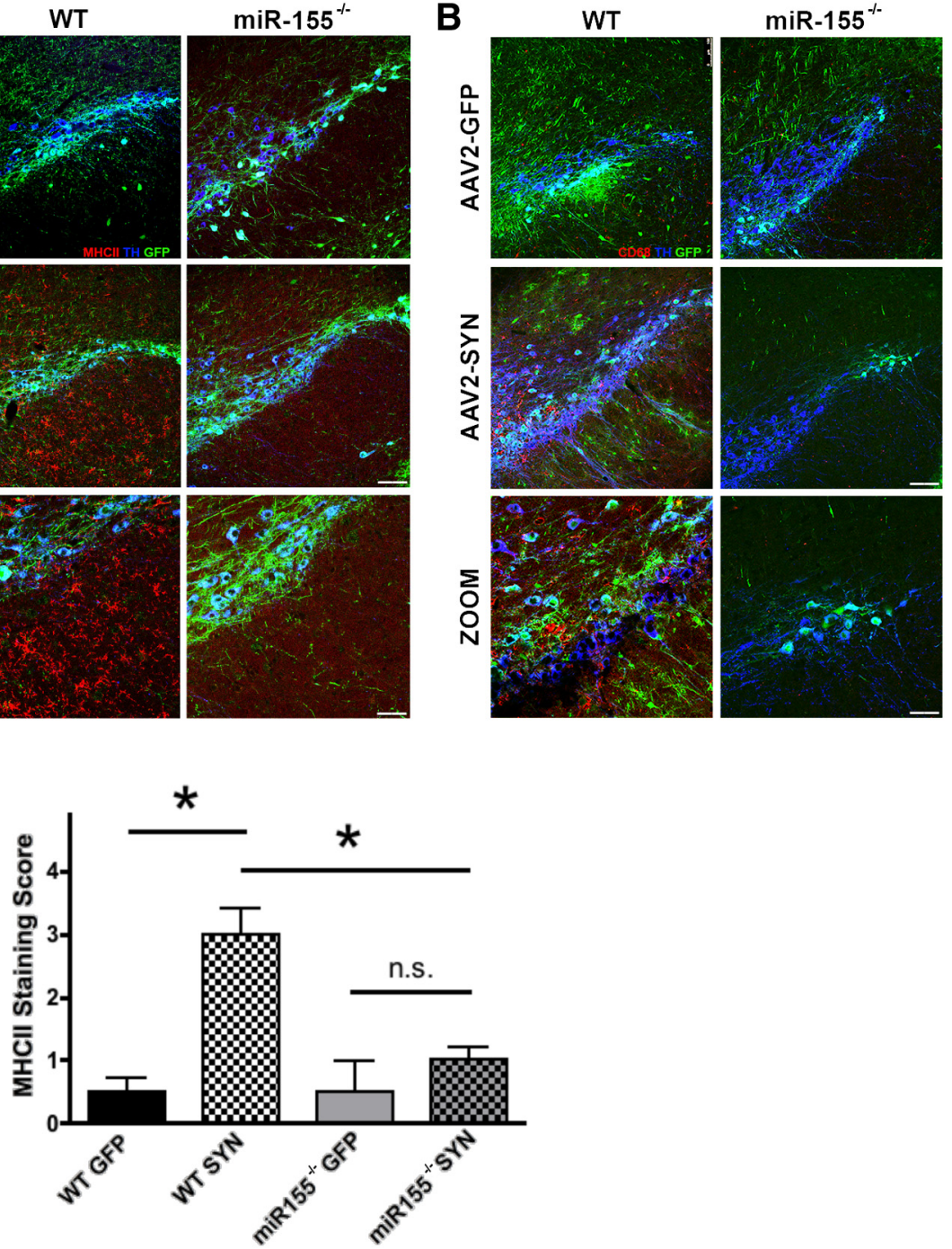

Figure 2. Knock-out of miR-155 attenuates AAV2-SYN induced microgliosis in vivo. A, Increased expression of MHCII (red) in surrounding AAV2-SYN (green-infected TH ${ }^{+}$neurons (blue) in the SNpc at 4 weeks after transduction of the virus. This increase in microscope and processed using Adobe Photoshop. Scale bar, $100 \mu \mathrm{m}$. B, Increased CD68 (red) in WT animals at 4 weeks after

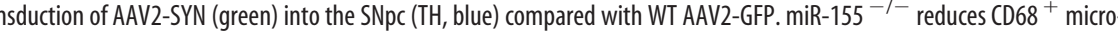
in response to overexpression of $\alpha$-syn. Scale bar, $50 \mu \mathrm{m}$. C, Quantification of MHCIl intensity assessed after DAB staining of sections for MHCII and TH. Coded slides were assessed a score of 0 (no staining)- 4 (most intense staining) based on the expression of MHCII in the SNpc. Quantification performed with $n=6$ per group and statistical significance assessed using a Kruskal-Wallis test with Dunn's multiple-comparisons test $(p=0.0146)$.

SNpc 6 months after transduction with the viral vector in WT and

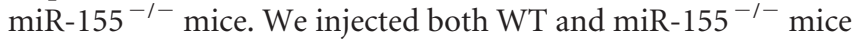
( $n=10$ per group). $\mathrm{TH}^{+}$neurons were counted using unbiased stereology to assess $\alpha$-syn-induced neurodegeneration (Fig. $3 A, B)$. In WT mice, we observed a $29.7 \pm 6.6 \%$ loss of $\mathrm{TH}^{+}$ neurons in WT animals transduced with AAV2-SYN compared with AAV2-GFP $(p<0.001$, one-way ANOVA with Bonferroni post hoc analysis). This loss was markedly attenuated in miR$155^{-1-}$ mice, in which we observed no statistically significant loss of $\mathrm{TH}^{+}$neurons in AAV2-SYN-injected animals.

miR-155 is required for $\alpha$-syn-induced MHCII and iNOS expression in microglia in vitro

Because our studies pointed to an important role of miR-155 in $\alpha$-syn-induced neuroinflammation and subsequent neurodegeneration in vivo, we wanted to examine the role of miR-155 specifically 
A
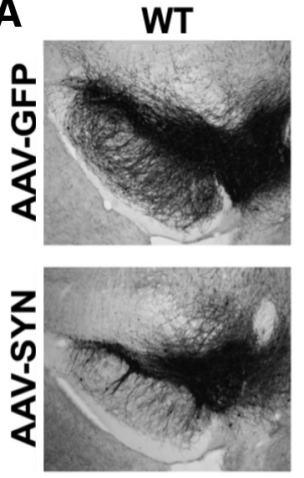

B

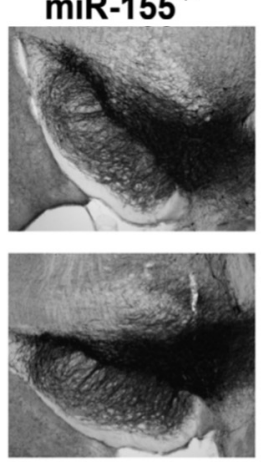

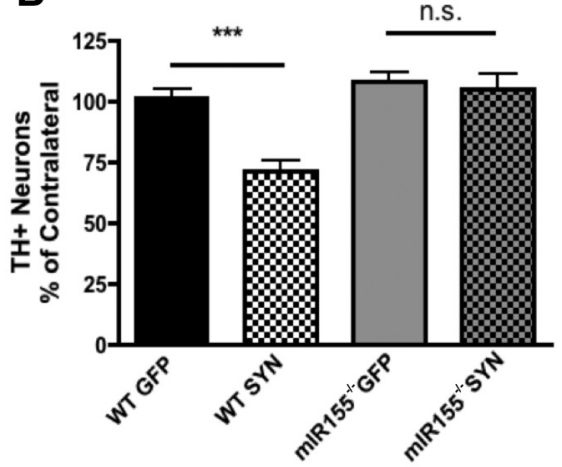

Figure 3. miR-155 knock-out blocks neurodegeneration induced by AAV2-SYN in vivo. Six months after transduction of virus, dopaminergic, $\mathrm{TH}^{+}$neurons were quantified using unbiased stereology to assess neurodegeneration. $A$, Representative images ipsilateral to the injection of either AAV2-GFP or AAV2-SYN that are stained with DAB for the $\mathrm{TH}^{+}$neurons in both WT and miR-155 ${ }^{-1-}$ mice. $B$, Quantification of $\mathrm{TH}^{+}$neurons in the SNpc using unbiased stereology. There was a $29.72 \%$ loss of $\mathrm{TH}^{+}$ neurons in the SNpc of WT mice at 6 months after transduction of AAV2-SYN compared with AAV2-GFP ${ }^{* * *} p<0.0001, n=8-10$

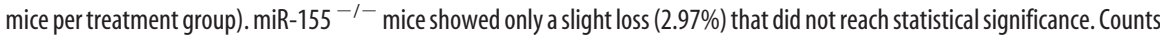
are expressed as a percentage of neurons in each ipsilateral SNpc compared with neurons in the contralateral SNpc of the same animal. Data were analyzed using one-way ANOVA with Bonferroni's multiple-comparison post hoc test.

in the response of microglia to fibrillary $\alpha$-syn and to determine whether these effects were cell autonomous. Several different forms of aggregated $\alpha$-syn have been described as activators of microglial cells in vitro (Reynolds et al., 2008a; Reynolds et al., 2008b; Cao et al., 2010; Lee et al., 2010; Harms et al., 2012).We used $\alpha$-syn fibrils made from recombinant WT human $\alpha$-syn (Volpicelli-Daley et al., 2011; Luk et al., 2012b). Two hours after addition of sonicated fibrils (200 $\mathrm{ng} / \mathrm{ml}$ ), WT microglia became activated and increased their expression of MHCII and iNOS, as seen by immunocytochemistry (Fig.

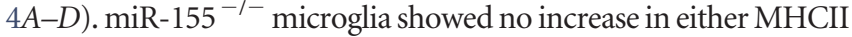
or iNOS expression $2 \mathrm{~h}$ after similar treatment with $\alpha$-syn fibrils. To determine whether restoration of miR-155 alone was sufficient to restore the inflammatory response, we treated the miR-155 ${ }^{-1-}$ microglia with an oligonucleotide mimic of miR-155 (Divekar et al., 2011; Long et al., 2013). At a concentration of 1 pM, miR-155 mimic alone did not activate miR-155 ${ }^{-/-}$microglia directly, but did reconstitute the inflammatory response to $\alpha$-syn fibrils (Fig. $4 E$ ).

\section{Discussion}

In this study, we examined the role of miR-155 signaling in $\alpha$-syn-mediated inflammation and neurodegeneration. Using an in vivo model in which $\alpha$-syn is overexpressed, we found early upregulation of miR-155 expression. Mice with deletion of miR155 showed markedly attenuated inflammatory responses to AAV-SYN and protection against dopaminergic neuron loss. The effects of miR-155 on microglial inflammatory responses to $\alpha$-syn fibrils are at least partly cell autonomous: they are absent in microglia with deletion of miR-155 and restored by molecular mimics of miR-155. These results suggest that miR-155 is involved early in PD pathogenesis and is important for initiating the inflammatory response to $\alpha$-syn.

microRNA-155 has been identified previously as a key regulator of several other neuroinflammatory disorders. In MS, miR155 is upregulated in brain lesions of patients postmortem, in peripheral blood mononuclear cells from living patients, and in experimental autoimmune encephalomyelitis (EAE), a mouse model for multiple sclerosis (Lopez-Ramirez et al., 2014; Devier et al., 2015). miR-155 also plays a significant role in the T-cell differentiation associated with MS and EAE, which affects the course and severity of disease directly (Zhang et al., 2014). AD is associated with increased miR-155 in CSF (Alexandrov et al., 2012). In the SOD $1^{\text {G93A }}$ mouse model of ALS, inhibition of miR-155 signaling with oligonucleotides causes widespread upregulation of miR-155 targets and extends survival by 38\% (Koval et al., 2013). Genetic knock-out of miR-155 in the SOD1 G93A mice restores microglial molecular signatures and also increases survival of the mice (Butovsky et al., 2015). Knock-out of miR-155 also attenuates injury and microglial activation after intrahippocampal injection of LPS (Woodbury et al., 2015). These studies demonstrate the importance of miR-155 in regulating inflammatory cascades in a broad spectrum of neurodegenerative disorders, specifically highlighting its involvement in immune cell reactivity and dysfunction.

In these studies, we examined the role of miR-155 in $\alpha$-syn-elicited inflammation in vivo. We have shown previously that overexpression of $\alpha$-syn via AAV elicits an inflammatory response, characterized by increased proinflammatory cytokine production, MHCII activation, microgliosis, IgG deposition, and lymphocyte infiltration (Theodore et al., 2008; Cao et al., 2010; Harms and Tansey, 2013). Using a mouse in which miR-155 is knocked out and prevents the generation of mature miR-155 sequences from acting on immune signaling pathways, we observed attenuation of $\alpha$-syn-induced MHCII expression and reactive microgliosis at 4 weeks after transduction (Fig. $2 A-C$ ) and prevention of IgG deposition in the ipsilateral hemisphere (data not shown). We also observed that deletion of miR-155 led to inhibition of microglial responses to aggregated $\alpha$-syn in vitro. These data indicate that miR-155 is critical for immune activation by aggregated $\alpha$-syn and works at least in part by modulating the response of microglia directly.

Our study also investigated whether miR- $155^{-1-}$ would attenuate $\alpha$-syn-induced neurodegeneration. At 6 months after transduction, WT mice transduced with AAV2-SYN reproducibly exhibit an $\sim 30 \%$ loss of $\mathrm{TH}^{+}$dopaminergic neurons in the ipsilateral SNpc. In this study, in contrast to a $29.7 \%$ loss of $\mathrm{TH}^{+}$ neurons in WT mice injected with AAV2-SYN, mice lacking miR-155 demonstrated near complete neuroprotection with only a $2.97 \%$ loss of $\mathrm{TH}^{+}$neurons in the injected SNpc 6 months after transduction. This is a very striking degree of neuroprotection, similar to what we have observed previously with knock-out of the MHCII signaling pathways (Harms et al., 2013).

In these studies, we used an in vitro approach to study directly the role of miR-155 in the microglial response to aggregated $\alpha$-syn. Aggregated $\alpha$-syn has been shown to activate microglia through binding of surface receptors of immune cells, particularly microglial cells (Zhang et al., 2005; Reynolds et al., 2008a; Lee et al., 2010; Cao et al., 2012; Harms et al., 2012). Our previous studies used large, aggregated species of $\alpha$-syn to activate primary microglia cells in culture (Cao et al., 2010; Harms et al., 2013). Others have reported that various modified forms of $\alpha$-syn, including nitrated and fibrillar preparations, can elicit an inflammatory response (Klegeris et al., 2008; Reynolds et al., 2008b; Codolo et al., 2013; Roodveldt et al., 2013). In the current studies, we used sonicated $\alpha$-syn fibrils (Volpicelli-Daley et al., 2014) because we have found these to be a particularly potent and reli- 
A
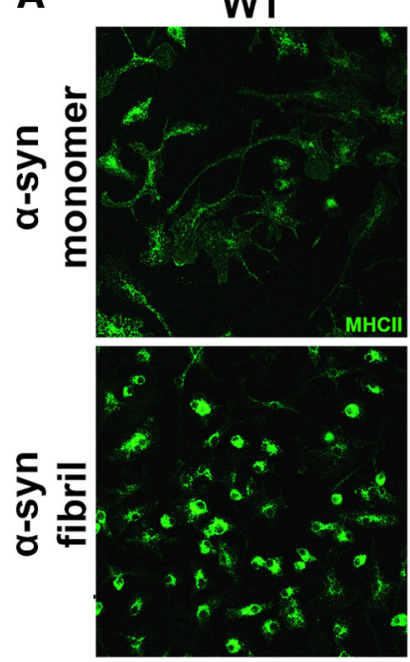

C
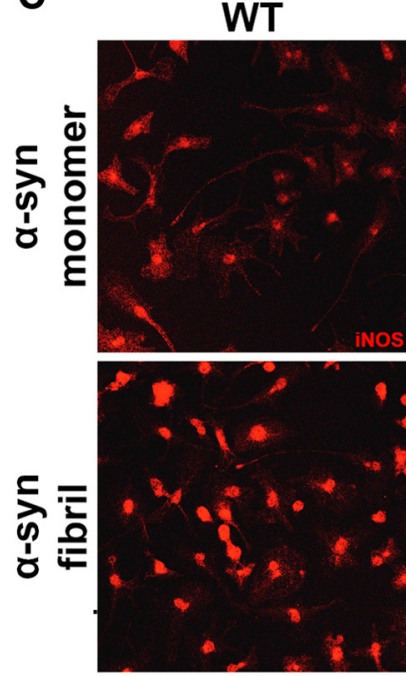

miR-155
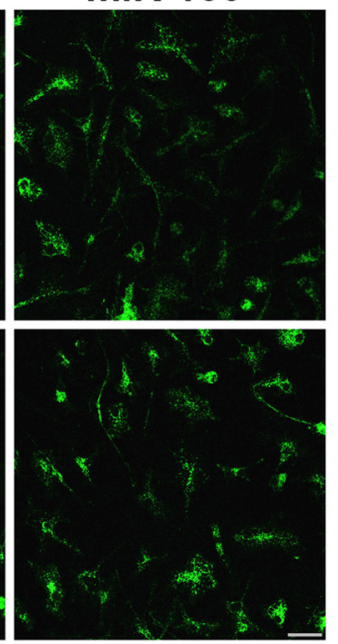

$\operatorname{miR}-155^{-1-}$
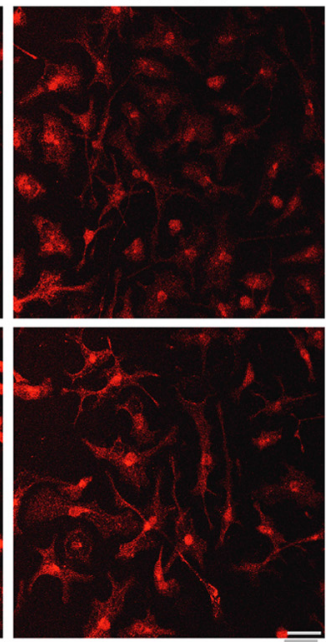

B

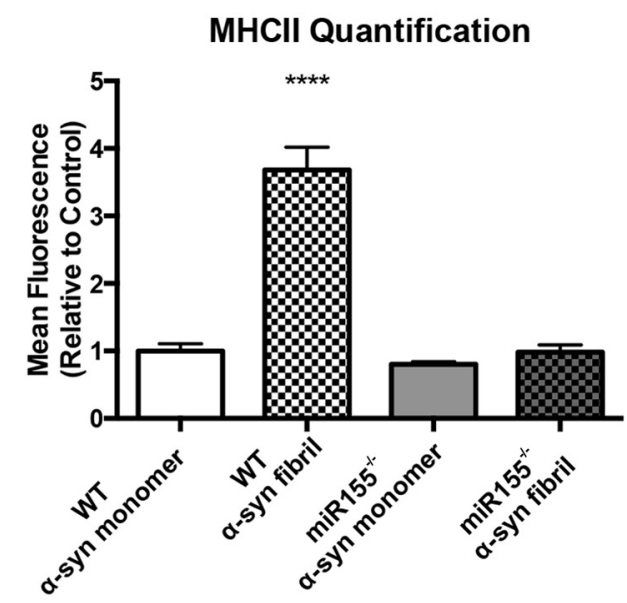

D

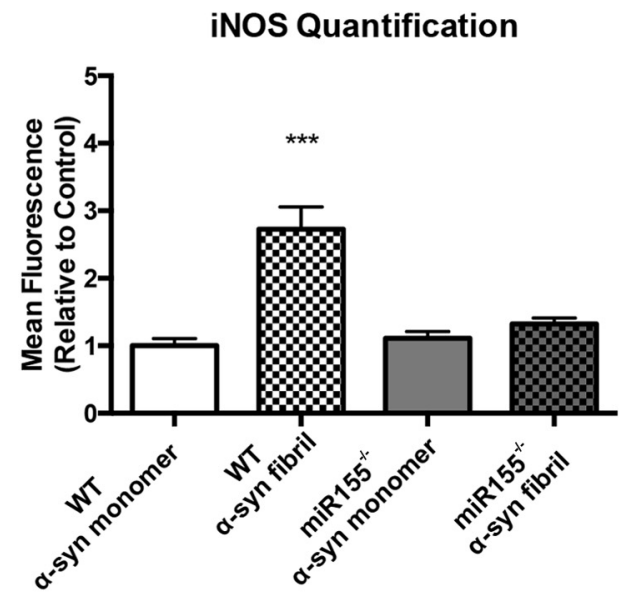

E

\section{iNOS Quantification}

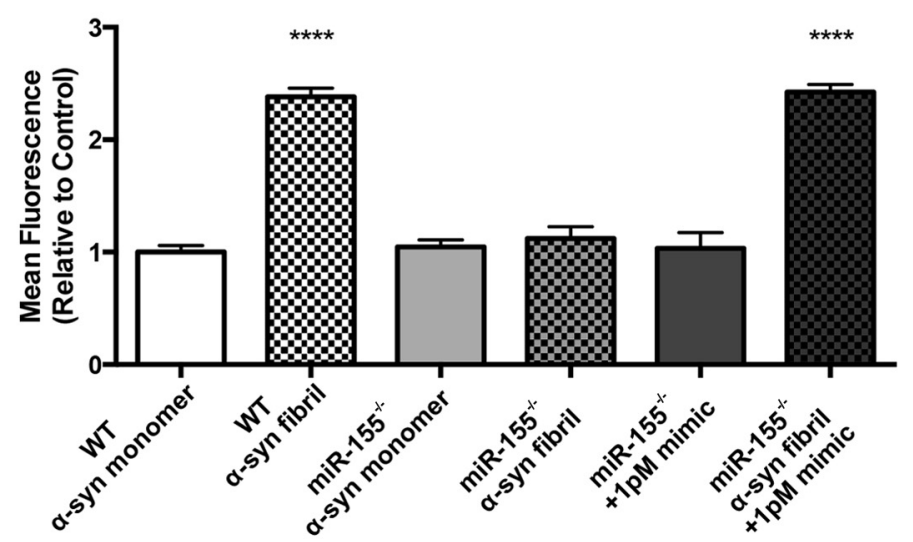

Figure 4. miR-155 is required for upregulation of microglial MHCII and iNOS in response to fibrillized $\alpha$-syn. Using primary microglia derived from postnatal day $0-3$ mouse pups, proinflammatory markers were assessed in $\alpha$-syn-reactive microglia from WT and miR-155 ${ }^{-1-}$ mice. Scale bar, $25 \mu \mathrm{m}$. A, B, Primary microglia were treated with $\alpha$-syn fibrils ( $200 \mathrm{ng} / \mathrm{ml}$ ) for $2 \mathrm{~h}$. Increases in MHCll expression (green) were captured using immunocytochemistry. Microglial fluorescence showed increased MHCll expression in response to the addition of $\alpha$-syn fibrils and this finding was ablated in microglia lacking miR-155. C, D, Imaging and quantification of iNOS staining (red) in microglia after the addition of $\alpha$-syn fibrils (200 ng/ml) for $2 \mathrm{~h}$ in WT and miR-155 ${ }^{-1-}$ microglia. Increased iNOS staining was seen in WT microglia after the addition of $\alpha$-syn and this increased expression of iNOS was not seen in miR-155 ${ }^{-/-}$microglia. $\boldsymbol{E}$, Independent experiment quantifying

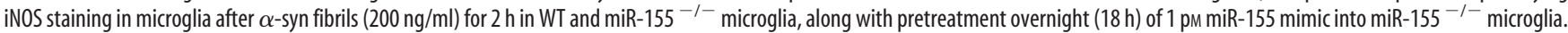
Quantification of the fluorescence was performed using ImageJ to analyze the mean fluorescence of individual microglia. Four images were taken per chamber of a chamber slide that contains four chambers and quantification is reported as the mean value with SEM. Statistics were run using ${ }^{* * *} p<0.001$, ${ }^{* * *} p<0.0001$, one-way ANOVA with Tukey's multiple-comparisons test. 
able activator of microglia in vitro. Upon stimulation with 200 $\mathrm{ng} / \mathrm{ml} \alpha$-syn fibrils, primary microglia exhibited a proinflammatory response characterized by a robust induction of iNOS expression and an increase in surface MHCII expression. As a control, we used $\alpha$-syn monomer, which did not elicit a microglial response (data not shown). The inflammatory reaction to $\alpha$-syn fibrils was completely absent in primary microglia derived from miR-155 $5^{-1-}$ mice (Fig. $4 A-D$ ). We also found that the inflammatory response to $\alpha$-syn fibrils was restored by addition of a synthetic mimic of miR-155, suggesting that activation of this pathway is not only necessary, but also sufficient for cellautonomous effects on microglia. It will be important to extend these studies with miR mimics and other modulators to the in vivo setting.

These studies suggests that miR-155 plays a key role in the early response to abnormal forms of $\alpha$-syn in the brain and modulates the response of innate immune cells to synuclein-related antigens. Previously, we have described the importance of $\mathrm{MH}-$ CII in $\alpha$-syn-induced neuroinflammation and neurodegeneration (Harms et al., 2013). The miR-155 signaling described here likely lies upstream of MHCII antigen presentation because, by knocking out miR-155, we were able to prevent the induction of MHCII expression both in vivo and in vitro. Although we have focused on the intrinsic microglia of the brain, miR-155 also has a central role in regulating the inflammatory states of peripheral monocytes and may be important in modulating the migration and activation of these in neuroinflammatory and neurodegenerative disorders. microRNAs may be important both as targets for therapeutic intervention of PD and as a biomarkers for disease activity.

\section{References}

Alexandrov PN, Dua P, Hill JM, Bhattacharjee S, Zhao Y, Lukiw WJ (2012) microRNA (miRNA) speciation in Alzheimer's disease (AD) cerebrospinal fluid (CSF) and extracellular fluid (ECF). Int J Biochem Mol Biol 3:365-373. Medline

Allen Reish HE, Standaert DG (2015) Role of alpha-synuclein in inducing innate and adaptive immunity in Parkinson disease. J Parkinsons Dis 5:1-19. Medline

Appel SH (2012) Inflammation in Parkinson's disease: cause or consequence? Mov Disord 27:1075-1077. CrossRef Medline

Brochard V, Combadière B, Prigent A, Laouar Y, Perrin A, Beray-Berthat V, Bonduelle O, Alvarez-Fischer D, Callebert J, Launay JM, Duyckaerts C, Flavell RA, Hirsch EC, Hunot S (2009) Infiltration of CD4+ lymphocytes into the brain contributes to neurodegeneration in a mouse model of Parkinson disease. J Clin Invest 119:182-192. Medline

Butovsky O, Siddiqui S, Gabriely G, Lanser AJ, Dake B, Murugaiyan G, Doykan CE, Wu PM, Gali RR, Iyer LK, Lawson R, Berry J, Krichevsky AM, Cudkowicz ME, Weiner HL (2012) Modulating inflammatory monocytes with a unique microRNA gene signature ameliorates murine ALS. J Clin Invest 122:3063-3087. CrossRef Medline

Butovsky O, Jedrychowski MP, Cialic R, Krasemann S, Murugaiyan G, Fanek Z, Greco DJ, Wu PM, Doykan CE, Kiner O, Lawson RJ, Frosch MP, Pochet N, Fatimy RE, Krichevsky AM, Gygi SP, Lassmann H, Berry J, Cudkowicz ME, Weiner HL (2015) Targeting miR-155 restores abnormal microglia and attenuates disease in SOD1 mice. Ann Neurol 77: 75-99. CrossRef Medline

Cao S, Theodore S, Standaert DG (2010) Fcgamma receptors are required for NF-kappaB signaling, microglial activation and dopaminergic neurodegeneration in an AAV-synuclein mouse model of Parkinson's disease. Mol Neurodegener 5:42. CrossRef Medline

Cao S, Standaert DG, Harms AS (2012) The gamma chain subunit of Fc receptors is required for alpha-synuclein-induced pro-inflammatory signaling in microglia. J Neuroinflammation 9:259. CrossRef Medline

Codolo G, Plotegher N, Pozzobon T, Brucale M, Tessari I, Bubacco L, de Bernard M (2013) Triggering of inflammasome by aggregated alphasynuclein, an inflammatory response in synucleinopathies. PLoS One 8:e55375. CrossRef Medline
Devier DJ, Lovera JF, Lukiw WJ (2015) Increase in NF-kappaB-sensitive miRNA-146a and miRNA-155 in multiple sclerosis (MS) and proinflammatory neurodegeneration. Front Mol Neurosci 8:5. Medline

Divekar AA, Dubey S, Gangalum PR, Singh RR (2011) Dicer insufficiency and microRNA-155 overexpression in lupus regulatory T cells: an apparent paradox in the setting of an inflammatory milieu. J Immunol 186: 924-930. CrossRef Medline

Femminella GD, Ferrara N, Rengo G (2015) The emerging role of microRNAs in Alzheimer's disease. Front Physiol 6:40. Medline

Gerhard A, Pavese N, Hotton G, Turkheimer F, Es M, Hammers A, Eggert K, Oertel W, Banati RB, Brooks DJ (2006) In vivo imaging of microglial activation with [11C](R)-PK11195 PET in idiopathic Parkinson's disease. Neurobiol Dis 21:404-412. CrossRef Medline

Hamza TH, Zabetian CP, Tenesa A, Laederach A, Montimurro J, Yearout D, Kay DM, Doheny KF, Paschall J, Pugh E, Kusel VI, Collura R, Roberts J, Griffith A, Samii A, Scott WK, Nutt J, Factor SA, Payami H (2010) Common genetic variation in the HLA region is associated with late-onset sporadic Parkinson's disease. Nat Genet 42:781-785. CrossRef Medline

Harms AS, Tansey MG (2013) Isolation of murine postnatal brain microglia for phenotypic characterization using magnetic cell separation technology. Methods Mol Biol 1041:33-39. CrossRef Medline

Harms AS, Lee JK, Nguyen TA, Chang J, Ruhn KM, Treviño I, Tansey MG (2012) Regulation of microglia effector functions by tumor necrosis factor signaling. Glia 60:189-202. CrossRef Medline

Harms AS, Cao S, Rowse AL, Thome AD, Li X, Mangieri LR, Cron RQ, Shacka JJ, Raman C, Standaert DG (2013) MHCII is required for alphasynuclein-induced activation of microglia, $\mathrm{CD} 4 \mathrm{~T}$ cell proliferation, and dopaminergic neurodegeneration. J Neurosci 33:9592-9600. CrossRef Medline

Hirsch EC, Hunot S (2009) Neuroinflammation in Parkinson's disease: a target for neuroprotection? Lancet Neurol 8:382-397. CrossRef Medline

Junker A, Krumbholz M, Eisele S, Mohan H, Augstein F, Bittner R, Lassmann H, Wekerle H, Hohlfeld R, Meinl E (2009) microRNA profiling of multiple sclerosis lesions identifies modulators of the regulatory protein CD47. Brain 132:3342-3352. CrossRef Medline

Klegeris A, Pelech S, Giasson BI, Maguire J, Zhang H, McGeer EG, McGeer PL (2008) Alpha-synuclein activates stress signaling protein kinases in THP-1 cells and microglia. Neurobiol Aging 29:739-752. CrossRef Medline

Koval ED, Shaner C, Zhang P, du Maine X, Fischer K, Tay J, Chau BN, Wu GF, Miller TM (2013) Method for widespread microRNA-155 inhibition prolongs survival in ALS-model mice. Hum Mol Genet 22:4127-4135. CrossRef Medline

Lee EJ, Woo MS, Moon PG, Baek MC, Choi IY, Kim WK, Junn E, Kim HS (2010) Alpha-synuclein activates microglia by inducing the expressions of matrix metalloproteinases and the subsequent activation of proteaseactivated receptor-1. J Immunol 185:615-623. CrossRef Medline

Liu G, Abraham E (2013) microRNAs in immune response and macrophage polarization. Arterioscler Thromb Vasc Biol 33:170-177. CrossRef Medline

Long L, Yu P, Liu Y, Wang S, Li R, Shi J, Zhang X, Li Y, Sun X, Zhou B, Cui L, LiZ (2013) Upregulated microRNA-155 expression in peripheral blood mononuclear cells and fibroblast-like synoviocytes in rheumatoid arthritis. Clin Dev Immunol 2013:296139. Medline

Lopez-Ramirez MA, Wu D, Pryce G, Simpson JE, Reijerkerk A, King-Robson J, Kay O, de Vries HE, Hirst MC, Sharrack B, Baker D, Male DK, Michael GJ, Romero IA (2014) microRNA-155 negatively affects blood-brain barrier function during neuroinflammation. FASEB J 28:2551-2565. CrossRef Medline

Louafi F, Martinez-Nunez RT, Sanchez-Elsner T (2010) microRNA-155 targets SMAD2 and modulates the response of macrophages to transforming growth factor-\{beta\}. J Biol Chem 285:41328-41336. CrossRef Medline

Luk KC, Song C, O'Brien P, Stieber A, Branch JR, Brunden KR, Trojanowski JQ, Lee VM (2009) Exogenous alpha-synuclein fibrils seed the formation of Lewy body-like intracellular inclusions in cultured cells. Proc Natl Acad Sci U S A 106:20051-20056. CrossRef Medline

Luk KC, Kehm VM, Zhang B, O’Brien P, Trojanowski JQ, Lee VM (2012a) Intracerebral inoculation of pathological alpha-synuclein initiates a rapidly progressive neurodegenerative alpha-synucleinopathy in mice. J Exp Med 209:975-986. CrossRef Medline

Luk KC, Kehm V, Carroll J, Zhang B, O’Brien P, Trojanowski JQ, Lee VM 
(2012b) Pathological alpha-synuclein transmission initiates Parkinsonlike neurodegeneration in nontransgenic mice. Science 338:949-953. CrossRef Medline

McGeer PL, Itagaki S, Boyes BE, McGeer EG (1988) Reactive microglia are positive for HLA-DR in the substantia nigra of Parkinson's and Alzheimer's disease brains. Neurology 38:1285-1291. CrossRef Medline

Mogi M, Harada M, Riederer P, Narabayashi H, Fujita K, Nagatsu T (1994a) Tumor necrosis factor-alpha (TNF-alpha) increases both in the brain and in the cerebrospinal fluid from parkinsonian patients. Neurosci Lett 165: 208-210. CrossRef Medline

Mogi M, Harada M, Kondo T, Riederer P, Inagaki H, Minami M, Nagatsu T (1994b) Interleukin-1 beta, interleukin-6, epidermal growth factor and transforming growth factor-alpha are elevated in the brain from parkinsonian patients. Neurosci Lett 180:147-150. CrossRef Medline

Moore CS, Rao VT, Durafourt BA, Bedell BJ, Ludwin SK, Bar-Or A, Antel JP (2013) miR-155 as a multiple sclerosis-relevant regulator of myeloid cell polarization. Ann Neurol 74:709-720. CrossRef Medline

O'Connell RM, Chaudhuri AA, Rao DS, Baltimore D (2009) Inositol phosphatase SHIP1 is a primary target of miR-155. Proc Natl Acad Sci U S A 106:7113-7118. CrossRef Medline

Ponomarev ED, Veremeyko T, Weiner HL (2013) microRNAs are universal regulators of differentiation, activation, and polarization of microglia and macrophages in normal and diseased CNS. Glia 61:91-103. CrossRef Medline

Ramsey CP, Tansey MG (2014) A survey from 2012 of evidence for the role of neuroinflammation in neurotoxin animal models of Parkinson's disease and potential molecular targets. Exp Neurol 256:126-132. CrossRef Medline

Reynolds AD, Kadiu I, Garg SK, Glanzer JG, Nordgren T, Ciborowski P, Banerjee R, Gendelman HE (2008a) Nitrated alpha-synuclein and microglial neuroregulatory activities. J Neuroimmune Pharmacol 3:59-74. CrossRef Medline

Reynolds AD, Glanzer JG, Kadiu I, Ricardo-Dukelow M, Chaudhuri A, Ciborowski P, Cerny R, Gelman B, Thomas MP, Mosley RL, Gendelman HE (2008b) Nitrated alpha-synuclein-activated microglial profiling for Parkinson's disease. J Neurochem 104:1504-1525. CrossRef Medline

Roodveldt C, Labrador-Garrido A, Gonzalez-Rey E, Lachaud CC, Guilliams T, Fernandez-Montesinos R, Benitez-Rondan A, Robledo G, Hmadcha A, Delgado M, Dobson CM, Pozo D (2013) Preconditioning of microglia by alpha-synuclein strongly affects the response induced by toll-like receptor (TLR) stimulation. PLoS One 8:e79160. CrossRef Medline
St Martin JL, Klucken J, Outeiro TF, Nguyen P, Keller-McGandy C, CantutiCastelvetri I, Grammatopoulos TN, Standaert DG, Hyman BT, McLean PJ (2007) Dopaminergic neuron loss and up-regulation of chaperone protein $\mathrm{mRNA}$ induced by targeted over-expression of alpha-synuclein in mouse substantia nigra. J Neurochem 100:1449-1457. Medline

Thai TH, Calado DP, Casola S, Ansel KM, Xiao C, Xue Y, Murphy A, Frendewey D, Valenzuela D, Kutok JL, Schmidt-Supprian M, Rajewsky N, Yancopoulos G, Rao A, Rajewsky K (2007) Regulation of the germinal center response by microRNA-155. Science 316:604-608. CrossRef Medline

Theodore S, Cao S, McLean PJ, Standaert DG (2008) Targeted overexpression of human alpha-synuclein triggers microglial activation and an adaptive immune response in a mouse model of Parkinson disease. J Neuropathol Exp Neurol 67:1149-1158. CrossRef Medline

Thome AD, Standaert DG, Harms AS (2015) Fractalkine signaling regulates the inflammatory response in an alpha-synuclein model of Parkinson disease. PLoS One 10:e0140566. CrossRef Medline

Volpicelli-Daley LA, Luk KC, Patel TP, Tanik SA, Riddle DM, Stieber A, Meaney DF, Trojanowski JQ, Lee VM (2011) Exogenous alphasynuclein fibrils induce Lewy body pathology leading to synaptic dysfunction and neuron death. Neuron 72:57-71. CrossRef Medline

Volpicelli-Daley LA, Luk KC, Lee VM (2014) Addition of exogenous alphasynuclein preformed fibrils to primary neuronal cultures to seed recruitment of endogenous alpha-synuclein to Lewy body and Lewy neurite-like aggregates. Nat Protoc 9:2135-2146. CrossRef Medline

Woodbury ME, Freilich RW, Cheng CJ, Asai H, Ikezu S, Boucher JD, Slack F, Ikezu T (2015) miR-155 is essential for inflammation-induced hippocampal neurogenic dysfunction. J Neurosci 35:9764-9781. CrossRef Medline

Yang Y, Yang L, Liang X, Zhu G (2015) microRNA-155 promotes atherosclerosis inflammation via targeting SOCS1. Cell Physiol Biochem 36: 1371-1381. CrossRef Medline

Zhang J, Cheng Y, Cui W, Li M, Li B, Guo L (2014) microRNA-155 modulates Th1 and Th17 cell differentiation and is associated with multiple sclerosis and experimental autoimmune encephalomyelitis. J Neuroimmunol 266:56-63. CrossRef Medline

Zhang W, Wang T, Pei Z, Miller DS, Wu X, Block ML, Wilson B, Zhang W, Zhou Y, Hong JS, Zhang J (2005) Aggregated alpha-synuclein activates microglia: a process leading to disease progression in Parkinson's disease. FASEB J 19:533-542. CrossRef Medline 